\title{
CONCEPTUALISING HOW SMES INCORPORATE GREEN CONTENT IN THEIR WEBSITES
}

\author{
Craig M. Parker \\ Deakin University \\ craig.parker@deakin.edu.au \\ Emilia Bellucci \\ Deakin University \\ emilia.bellucci@deakin.edu.au \\ Luba Torlina \\ Monash University \\ Lioubov.Torlina@monash.edu \\ Bardo Fraunholz \\ Deakin University \\ bardo.fraunholz@deakin.edu.au \\ Ambika Zutshi \\ Deakin University \\ ambika.zutshi@deakin.edu.au
}

\begin{abstract}
This paper presents a framework on how Small and Medium Enterprises (SMEs) can proactively incorporate content relating to their ecological responsibility (or green) activities in their websites. SME studies offer limited guidance on, and conceptualisation of, how organisations can incorporate different types of content into their website designs. This paper addresses this problem by presenting the results of an exploratory, qualitative content analysis of Australian SME websites where emergent themes are interpreted using framing and legitimacy theories. The themes are grouped under three dimensions (location, presentation, and specificity) to form a theoretically-informed framework. The paper outlines how scholars can use the framework to develop models and carry out evaluations regarding how SMEs embed green content, and potentially other specific content types, in their websites. It also summarises how the framework can assist SMEs (or website developers serving them) make informed decisions regarding framing their websites as green, or de-emphasising this content, by paying attention to its location (e.g. homepage, navigation bars) and presentation (e.g. how paragraphs, images, etc are used) within webpages. The legitimacy or credibility of the green content can be enhanced using different types of specificity (e.g. statistics, detail of processes and actions, and third-party substantiation).
\end{abstract}

Keywords: Small and medium enterprises (SMEs), ecological responsibility, websites, content analysis, framework, green information systems

\section{INTRODUCTION}

Small and medium enterprises (SMEs) increasingly use websites to gain marketing advantage (e.g. Sensis, 2013), but their websites are often low quality due to their limited e-commerce/ marketing skills (Burgess, 2008; Fisher et al., 2007; Sanders \& Galloway, 2013). This has led scholars to develop frameworks for evaluating SME website content/designs which consider if particular content (e.g. 
policies, history) and design features (e.g. multimedia) are included (e.g. Bingley et al., 2010; Burgess, 2011; Sanders \& Galloway, 2013). However, very few studies look at how selected content is embedded in SME websites. Nevertheless, research in adjacent knowledge domains suggests that examining the effectiveness of SME websites requires considering not just if a specific type of content is included, but also how. This is important because, for example, variation in how privacy content is embedded can effect consumer behaviour, online sales (Tsai et al., 2011) and trust (Resnick \& Montania, 2003). Our study thus addresses the above mentioned gap in the literature and suggests a framework which can assist SMEs to decide how to embed selected content in their websites, and which enables scholars to explore this in future evaluations of SME websites.

The paper focuses on "green content" which some SMEs embed in their websites to promote "green activities" resulting in reduced negative environmental impact (Parker \& Scheepers, 2012), such as recycling to reduce landfill and reducing energy to lower carbon emissions (Parker et al., 2009). Green content is an interesting case for identifying how specific information can be embedded because SMEs use information variously to promote green activities, attract clients and improve their reputation (Williams \& Schaefer, 2013). For instance, for some of these SMEs being green is core business (Spence et al., 2011) and they may include green content prominently. For others being green is not core business and they thus find it hard to design websites to appeal both to green customers and those who are not interested in their green activities (Gueben \& Skerratt, 2007), so they may need to embed green content subtly.

This study makes three contributions to IS knowledge when answering the following research question: "What theory helps conceptualise how SMEs embed green content in their websites?" First, it fills a gap in knowledge concerning how SMEs can incorporate a specific content type by presenting a framework for exploring how SMEs embed green content in their websites, and suggests how it can be used potentially to examine other content types. Second, the paper identifies, and then reports on using, framing and legitimacy theories to show how they inform the framework. This is important because IS studies of SME websites do not provide insights into theory which could be used for such a framework. Third, this study addresses the call by some scholars for the IS field to examine the nexus of IS, organisations and the environment (e.g. Melville, 2010), including for SMEs (Coffey et al., 2013; Elliot, 2009), known as "green IS" (Watson et al., 2010). This includes how SMEs can use websites to communicate green activities (Parker et al., 2010).

The rest of the paper is structured as follows. First, it reviews SME-specific studies (because they are different to large firms) relating to their websites and/or green activities to argue the need for a framework to conceptualise how SMEs embed green content in their websites. The paper then summarises a three-staged study resulting in a theoretically-informed framework: 1) an inductive, qualitative content analysis of Australian SME websites which led to identifying themes relating to how they embedded green content; 2) a search of literature on large firms to identify theories to help conceptualise and interpret the themes; and 3) a reinterpretation of the stage 1 data using the stage 2 theories which lead to new insights and the framework. The paper concludes by presenting the framework, summarising the study's limitations, and outlining the potential for scholars to use the framework for other content types and to inform website design guidelines which can be developed for SMEs.

\section{LITERATURE REVIEW}

IS researchers have undertaken SME-specific research for over a decade (Keller \& Coulthard, 2013) to examine such issues as website adoption barriers/drivers and benefits (see reviews by Parker \& Castleman, 2007; Wymer \& Regan, 2011). SME-specific research is required because they are different to large firms, such as having limited financial/personnel resources (Jones et al., 2014), and hence findings from studies of large firms may not always apply to SMEs (MacGregor \& Kartiwi, 2010). 
Many SMEs, despite their limitations, have found websites can promote them and their products/services, and help them to gain new customers and sell online (e.g. Jones et al., 2014; Saffu et al., 2012; Sensis, 2013).

IS scholars have conducted content analyses of SME websites to determine if they include specific content (e.g. firm history, policies, customer reviews and product details) and design features (e.g. transactions, interactivity and multimedia) (Alonso Mendo \& Fitzgerald, 2005; Andreopoulou et al., 2009; Bingley et al., 2010; Burgess, 2011; Neilson et al., 2010). Some studies have created stage models or frameworks based on this work (Alonso Mendo \& Fitzgerald, 2005; Burgess et al., 2011; Cooper \& Burgess, 2000; Zhu et al., 2009) to compare industries, evaluate website maturity within an industry and to compare website changes over time. Other IS scholars have reported that SME websites are often low quality because SMEs have limited resources and expertise with e-commerce and marketing (Burgess, 2008; Fisher et al., 2007; Sanders \& Galloway, 2013). This highlights the need for SMEspecific studies which leads to guidance on how SMEs can design their websites in an effective manner within their constraints. This has led to research, for instance, on process models to help SMEs decide what website content/features to include (Burgess, 2008).

Few IS studies, however, focus on a specific content type and explore how it is embedded in SME websites. This is important because, for instance, experimental studies of consumers suggest that how privacy content is embedded in websites (e.g. top versus bottom of homepages) influences online sales (Tsai et al., 2011) and trust (Resnick \& Montania, 2003). This calls for a framework relating to how specific content types can be embedded in SME websites, because such design decisions may affect whether visitors find the content and how they act upon it. Only two studies (Dincer \& Dincer, 2010; Parker et al., 2010) had findings relevant to how a specific content type (green/social responsibility content and green content respectively) was embedded in SME websites: where it was in website hierarchies; whether webpages were dedicated to the content; and if navigation titles related to the content. However, neither study developed a framework relating to how the content was embedded.

We noted earlier that we selected green content as the specific content type for this paper because some SMEs are increasingly engaging in green activities (e.g. Revell et al., 2010; Williams \& Schaefer, 2013) and proactively promoting their efforts online (Dincer \& Dincer, 2010; Nielsen \& Thomsen, 2009) to gain new customers and improve their reputation (Gueben \& Skerratt, 2007). The green activities of SMEs include reducing waste and carbon emissions, procuring green suppliers and/or from green suppliers, requiring staff to engage in recycling, offering products/services which enable customers to be green (Aragon-Correa et al., 2008; Hofmann et al., 2012; Revell et al., 2010; Williams \& Schaefer, 2013) and reducing the environmental impact of their IS/IT (Coffey et al., 2013; Dick \& Burns, 2011; Elliot, 2009). In this paper we focus on text, images and other semiotic forms which are used on SME websites to convey these green activities, and on identifying themes relating to how this green content was embedded in SME websites to inform the development of our framework.

This paper contributes to the growing green IS field, as mentioned earlier. Green IS research explores: 1) how organisations can reduce the negative impact of their IS infrastructure; and 2) how organisations can use IS to reduce their (and/or encourage their stakeholders such as customers to reduce their) impact (Lei \& Ngai, 2013; Melville, 2010; Watson et al., 2010). While most green IS research has focused on large firms, SME studies in the first (e.g. Dick \& Burns, 2011; Elliot, 2009) and second (e.g. Coffey et al., 2013; Nowduri \& Al-Dossary, 2012) areas of green IS are now more common. This paper falls into the second category because it explores how SMEs can use websites to communicate how they reduce and/or how their customers can reduce their environmental impact (Parker et al., 2010).

We were especially interested in the potential of theory to inform our framework and help to conceptualise how green content can be embedded in SME websites. This was important because some authors (Alonso-Mendo et al., 2009; Alonso Mendo \& Fitzgerald, 2005) used theory to underpin their 
framework for evaluating how SME website designs change over time and found theory resulted in richer interpretations of findings. Our review of SME studies did not reveal theories suitable for our purpose. This led to the research question: "What theory helps conceptualise how SMEs embed green content in their websites?"

\section{RESEARCH APPROACH}

The above-mentioned research question was answered using a three-stage research approach.

Stage 1: The first stage involved analysing relevant SME literature and collecting/analysing empirical data. The IS literature was reviewed (see above) for insights relating to embedding specific content on SME websites. Data collection involved selecting SME websites which proactively promoted green activities and incorporated green content in different ways, but manageable in number to facilitate an in-depth semiotic analysis to identify emergent themes. This is similar to the approach used by Bingley et al. (2010) to develop their classification scheme for analysing what types of Web 2.0 features were used on SME websites. Combining our findings from SME specific literature and data analysis enabled us to identify themes regarding the different ways green content can be embedded in SME websites.

Stage 2: Our stage 1 literature review did not reveal theories suitable for conceptualising how SME websites embed specific content. This meant we had to collect additional literature to identify suitable theory to "foster conceptualisation" (Strauss \& Corbin, 1998) of the themes from stage 1. Stage 2 therefore involved reviewing studies of large firms' websites to identify theory they used to conceptualise how specific content was embedded, and to underpin richer interpretation of our Stage 1 themes. Framing and legitimacy theories have been used in studies of large firms, so we decided to employ them for our research on SMEs.

Stage 3: The stage 1 data and emergent themes were then reinterpreted using theory identified in stage 2. More specifically, further analysis of the themes identified during the first stage, through the lenses of legitimacy and framing theories, revealed new insights contributing to the final framework. This paper shows how theory can inform a framework which conceptualises how green content can be embedded in SME websites.

There are, arguably, elements of a grounded theory approach in our three-stage research method. Nonetheless, we do not consider our qualitative study as an exemplar of grounded theory because our study involves conceptions based on the work of others (Goulding, 2005) and because we are not building theory from empirical data alone.

The next sections explain the three stages in more detail, with particular emphasis on Stage 3.

\section{STAGE 1: DATA COLLECTION AND PRELIMINARY ANALYSIS}

\section{Sampling and data collection}

Stage 1 required a sufficient number of SME websites to enable in-depth semiotic analysis leading to emergent themes regarding the different ways SMEs can proactively embed green content. We chose Australian websites because adoption rates in Australia had reached levels where many SMEs own and use websites for promotion (Sensis, 2013). Australian SME websites were identified from the Yahoo Small Business Directory (2010) database in which SMEs can promote themselves proactively by selecting their industry sector and entering details such as product/service descriptions and an optional hyperlink to their website.

We focused on SMEs in the Information Media and Telecommunications (IMT) sector, as labelled in the Yahoo directory, because most had websites and there was evidence (Elliot, 2009; Parker et al., 2010) some Australian IMT SMEs engaged in green activities. The IMT sector included Internet service 
providers, website and web portal developers, Internet and paper-based printers/publishers, (Internet) broadcasters and motion picture/sound recorders. We identified all the IMT SME websites which mentioned green activities typical of SMEs as found and listed in detail by Parker et al. (2013). For each website we archived the homepage and webpages including green content because websites are highly dynamic (Alonso Mendo \& Fitzgerald, 2005). This ensured we could analyse the data in its original context without concern the website would disappear or its content would change. Two authors independently analysed all the identified websites and, after reaching consensus over embedded content about green activities, there were 12 IMT SME websites. Table 1 summarises the products/services of each SME and the pseudonyms used to identify each website.

The use of 12 Australian IMT SME websites has limitations such as emergent themes being more indicative of SMEs which proactively promote themselves and have more website design experience than those in other sectors, and omitting themes due to the small sample. Nevertheless, the 12 analysed websites were sufficient for answering our research question. First, sampling required identifying websites which embedded green content differently, and the findings revealed the same (e.g. some had prominent green content while others embedded it subtly). Second, 12 selected websites provided rich material from which themes emerged and were then reinterpreted in order to answer the research question. Answering the question necessitated in-depth semiotic analysis of about 40 webpages contained in those websites, including homepages and those stating green activities (and associated text and images). We completed analysis when no new information seemed to emerge from the research process, which indicated no need for further data collection (Strauss and Corbin, 1998). Finally, SMEs in other sectors have been found to commission IMT SMEs to develop their websites (Carey, 2008), so the framework will indirectly help such non-IMT SMEs.

\begin{tabular}{|l|l|}
\hline Pseudonym & Description of the products-services offered \\
\hline PrintMagazine & Published a magazine aimed at those in the vegan community. \\
\hline PrintProducts & Sold printed diaries and organisers via its website. \\
\hline WebHost & $\begin{array}{l}\text { Provided website hosting, domain name registration, and online tools } \\
\text { (website builders) so companies could design their own websites. }\end{array}$ \\
\hline WebDev & Designed websites in addition to the WebHost services. \\
\hline ePromo1, ePromo2 & $\begin{array}{l}\text { Provided graphics/logo design, email marketing and/or mobile phone } \\
\text { texting marketing services in addition to many of the WebDev services. }\end{array}$ \\
\hline $\begin{array}{l}\text { ePromoPrint1, } \\
\text { ePromoPrint2, } \\
\text { ePromoPrint3 }\end{array}$ & $\begin{array}{l}\text { Provided print marketing services in addition to many of the } \\
\text { ePromol/ePromo2 services. }\end{array}$ \\
\hline eCRM & $\begin{array}{l}\text { Provided Internet-based or client-run Customer Relationship Management } \\
\text { (CRM) software so companies could, for instance, manage their clients, } \\
\text { disseminate email newsletters, etc. }\end{array}$ \\
\hline Teleco1, Teleco2 & Provide information technology infrastructure \\
\hline
\end{tabular}

Table 1: Sample of Australian SME websites and their products-services

\section{Initial data analysis}

An exploratory, inductive and iterative approach was used to analyse the webpages containing green content to identify emergent themes concerning how the content was embedded. We employed some quantitative content analysis (e.g. sentence and paragraph counts) but we mainly used qualitative content analysis which involved identifying themes and capturing the effects of narrative and context on the meaning of the content (Beck et al., 2010). In this research, content analysis was used more broadly than solely for text analysis. Analysis of semiotics, which is at the core of content analysis (Beck et al., 2010), was employed to analyse, in addition to text, other elements such graphics and 
photos (Ramo, 2011). Elements specific to website design (e.g. menus, interactive links, icons) are important for web-based communications, and these elements distinguish websites from other types of media such as reports (Lodhia, 2012). These elements were included in our analysis as well.

We analysed the archived content for all the websites using a cyclic process similar to the collaborative coding and reconciliation procedure used by other scholars (e.g. Berente et al., 2011; Du \& Vieira, 2012). The process started by two authors independently analysing the websites to gain a general sense of how the green content was embedded in the designs and to identify initial themes. Themes were collated, differences in conclusions were discussed among all authors, and themes were consolidated. This approach was repeated with rounds of independent analysis by two authors (e.g. to look for detailed evidence of themes identified or consolidated after each round) followed by collation and discussions until we arrived at stable themes, based on consensus, grouped under three dimensions:

1) Location of the content: Emergent themes in this dimension related to green content being located on homepages and/or other webpages nested deeper in the website structures. These other webpages were either dedicated to green content or covered other topics but also included environment-related content to varying degrees.

2) Presentation of the content: Emergent presentation themes related to the use of logos, bullet points, paragraphs, hyperlinks and headings which emphasised or, in their absence, deemphasised the green content.

3) Specificity of the content: We found that the websites varied in terms of how specific or detailed they were about the firm's green activities. Emergent themes in this dimension included the use of statistics, the provision of information to enable visitors to cross-check the accuracy of the content using third party sources, and the amount of detail provided about the firm's green processes, actions and/or products-services.

\section{STAGE 2: THEORIES IDENTIFIED FROM THE LITERATURE ON LARGE FIRMS}

Stage 2 involved reviewing content analyses which examined how websites of large firms embedded specific content so that we could identify any respective use of theory. We found studies which had selected content relating to green activities (Cho \& Roberts, 2010; Hsieh, 2012; Yu et al., 2011), green activities and social responsibility (Du \& Vieira, 2012; Herzig \& Godemann, 2011; Lodhia, 2012), employment diversity (Mestre, 2011), drug benefits versus risks (Hicks et al., 2005), governance (Jiang et al., 2009) and privacy (LaRose \& Rifon, 2006; Park, 2011). Most did not employ theories but those which did used legitimacy theory (Cho \& Roberts, 2010; Du \& Vieira, 2012) and framing theory (Du \& Vieira, 2012). We therefore explored the literature on these theories further. We next present an overview of the two theories and why they had potential to help us conceptualise the dimensions and themes from stage 1 . The later section on stage 3 explores this in more depth.

Framing theory originates from the communications field (Chong \& Druckman, 2007) and has been used to examine how messages or ideas are presented or (de-)emphasised in mass media and to explore how these techniques influence the way in which receivers of the communication interpret the messages (Chong \& Druckman, 2007; de Vreese, 2005; Matthes \& Kohring, 2008). Framing mechanisms can include, among other things, presentation techniques which (de-)emphasise specific messages or ideas within media communications such as the use of headings, subheadings, logos, photos and photo captions (Tankard, 2001).

Du and Vieira (2012) identified two framing mechanisms which corresponded with our SME findings. The first was accessibility of green content from the homepage (location dimension), whereby the greater number of clicks it took to reach the green content the more the content was de-emphasised by the website. The second was the use of multimedia, which Du and Vieira (2012) stated 
enhanced/emphasised the green content because it often drew more attention than text alone. In the next section we present, additionally, three location and four presentation framing mechanisms which were evident on SME websites. In this paper we also consider how some location and presentation themes can influence the interpretation of green content from a framing perspective.

Legitimacy theory posits that entities such as organisations carry out actions and/or wish to be seen in a way which they perceive that stakeholders (e.g. customers) will find desirable or appropriate (Cho \& Roberts, 2010; Du \& Vieira, 2012). These perceptions are driven by socially constructed contexts such as social norms, ideologies and regulations (Du \& Vieira, 2012). Effective legitimacy management by organisations is largely achieved through marketing tactics whereby they can present themselves in a positive manner and enable them to gain credibility (Cho \& Roberts, 2010; Du \& Vieira, 2012). Organisations are often seen as more credible or legitimate if disinterested third-parties confirm the organisation's claims compared to instances where firms only make the claims themselves.

None of the legitimacy themes of Cho and Roberts (2010) were comparable to the emergent themes from our study. However, two legitimacy or communication tactics identified by Du and Vieira (2012) were similar to our SME website findings: presenting factual (statistical) statements about the firm's green practices; and presenting third-party evidence (e.g. accreditations) about the firm's green achievements. Our results also included SME-specific examples of these two themes, as well as introduced an additional specificity theme which was not evident in the work of Du and Vieira (2012).

\section{STAGE 3: THEME REINTERPRETATION USING FRAMING AND LEGITAMCY THEORIES}

Stage 3 involved reinterpreting the themes from each dimension arising in stage 1 using framing and legitimacy theories identified during stage 2 . This section reports the findings and these interpretations for each dimension in terms of framing theory (the location and presentation dimensions) or legitimacy theory (specificity dimension). The discussion of the findings suggests that the two theories can conceptualise the dimensions and associated themes which comprise this framework. For example, the next sections use the theories to explain the possible effects which many of the themes may have on website visitors, such as the ease of locating the content or how they may be interpreted.

\section{Location of green content}

The first dimension grouped themes relating to the location of green content on various types of webpages. For this dimension we considered that webpages communicated green activities if they had any image, word or phrase relating to a green activity. We examine the nature of this content later when exploring the presentation and specificity dimensions.

\section{“Clicks" from the homepage}

The first location theme related to the number of "clicks" from the homepage it took to reach green content and is a framing mechanism (Du \& Vieira, 2012) because the content is deemphasised with increasing numbers of clicks. We found that all but three websites had accessible green content because it was located on the homepage, so that their website was framed as green. We explore the nature of the green content and the degree of green framing on the homepages of these nine websites later when examining the presentation dimension.

The remaining three websites (eCRM, Teleco1 and Teleco2) required one click to a non-homepage before the green content was reached. This is shown in Figure 1 which summarises the webpages which included green content and how they could be reached on the websites. The elements of Figure 1 are explored in more detail in the next location sections. 


\begin{tabular}{|c|c|c|}
\hline & Main-menu titles & Sub-menu titles \\
\hline & $\begin{array}{l}\text { Dedicated webpage } \\
\text { - We plant trees (ePromoPrint5) }\end{array}$ & $\begin{array}{l}\text { Dedicated webpages } \\
\text { - Sustainability (ePromoPrint4) }\end{array}$ \\
\hline & $\begin{array}{l}\text { Subset webpages (the firm) } \\
\text { - About us (ePromoPrint4) } \\
\text { - Contact us (PrintMagazine) }\end{array}$ & $\begin{array}{l}\text {-We are carbon neutral (ePromo6) } \\
\text { - Green news (ePromoPrint3) } \\
\text { - Go green (WebDev1) }\end{array}$ \\
\hline K & $\begin{array}{l}\text { Subset webpages (policy) } \\
\text { - Philosophy (PrintMagazine) } \\
\text { - Ethical policy (eCRM) }\end{array}$ & $\begin{array}{l}\text { Subset webpages (stakeholders) } \\
\text { - Partners and affiliations (ePromo6) } \\
\text { - Community involvement (WebHost2) } \\
\text { - Community support (ePromo4) }\end{array}$ \\
\hline & $\begin{array}{l}\text { Subset webpages (product-service) } \\
\text { - Virtual servers (Teleco2) } \\
\text { - Recycled cards (ePromoPrint5) }\end{array}$ & $\begin{array}{l}\text { Subset webpage (news) } \\
\text { - News and media centre (WebHost } 2 \text { ) }\end{array}$ \\
\hline & About us & Subset webpages (products-services) \\
\hline & $\begin{array}{l}\text { Product-service main-menus } \\
\text { - Printing (ePromoPrint3) } \\
\text { - Debden Kyoto Edition (PrintProducts) } \\
\text { - Debden Enviro (PrintProducts) } \\
\text { - Leadership Eco Range (PrintProducts) }\end{array}$ & $\begin{array}{l}\text { - Recycled printing pricing (ePromoPrint3) } \\
\text { - Debden Kyoto A4 } 2 \text { Days to a Page (PrintProducts) } \\
\text { - Debden Enviro A5 Day to a Page (PrintProducts) } \\
\text { - Collins Leadership Eco Pocket Week to View (PrintProducts) }\end{array}$ \\
\hline & $\begin{array}{l}\text { - Leadership Eco Range (PrintProduc } \\
\text { Teleco1 in the field (Teleco1) }\end{array}$ & $\begin{array}{l}\text { Dedicated PDF page (policy) } \\
\text { - Environmental policy (Teleco1) }\end{array}$ \\
\hline
\end{tabular}

Figure 1: Location of green content on SME websites

\section{Dedicated versus subset webpages}

The second location theme concerned the type of non-homepages on which the content was located (see Figure 1): dedicated webpages where all content on the webpage was green; and subset webpages which covered other topics but also embedded some green content. Du and Vieira (2012) did not make this distinction and therefore did not identify this as a framing mechanism, possibly because the websites of the large firms they studied only had dedicated webpages. We consider this to be a framing mechanism, at least for SME websites, because dedicated versus subset webpages vary the emphasis of green content. For example, if a visitor accesses a dedicated webpage (e.g. ePromoPrint3, WebHost) they are more likely to notice the green content because it is all about the firm's green activities. This can be contrasted with subset webpages (e.g. ePromo1, Teleco2) where visitors need to read the webpage before they find the green content. In the presentation dimension we consider framing mechanisms which can be used to emphasise green content on subset webpages.

\section{Webpage framing using menu titles}

A third location theme related to the main-menu or sub-menu titles under which the dedicated and subset webpages were located within the website's structure (see Figure 1). Du and Vieira (2012) did not discuss how menu (or webpages) titles can be a framing mechanism in their own right. Instead, they listed examples of titles but used the titles collectively to describe how many clicks the green content was from the homepage. We believe titles are a framing mechanism in their own right by examining the nature of the titles to give richer insights into how they frame webpages. This can include how the titles contextualise the webpages and influence the ease by which webpages can be found on the website.

Figure 1 suggests that menu titles can frame dedicated and subset webpages. All dedicated webpages were framed using environment-related terms and thus made the green content easier to find or more accessible. But the titles also contextualised the webpages. WebHost's title "Green hosting" framed its dedicated webpage in a product-service context while other titles framed them in terms of the firm's news ("Green news"), identity ("We are carbon neutral"), policy or actions ("We plant trees"). Similar framing was evident on the subset webpages. Some had environment-related titles (ePromoPrint1, 
ePromoPrint3, PrintProducts) for subset webpages and framed them in a product-service context. The other subset webpages did not have environment-related terms and framed the content in terms of external stakeholder relationships (e.g. ePromo1), philosophy/policies (PrintMagazine, eCRM), news (WebHost) or products-services (Teleco2). In other words, the title of the webpage can contextualise how the webpages may be interpreted by the visitor: firm identity or principles; product-service offerings; news; actions; and stakeholder relationships. The lack of green titles also deemphasises the green content and could mean it is harder to locate.

The main-menu titles under which dedicated webpages were located (see Figure 1) may also influence how the webpages may be interpreted and how easily they would be found and accessed. All the dedicated webpages (except ePromoPrint3, WebHost) were located two clicks from the homepage under an "About us" type main-menus. This "About us" framing implies the owner-managers may have seen green activities as part of their own, or their firm's, values. This is interesting because this framing separates the product-service webpages from the green content so that visitors may not encounter the content if they only look for product-service information. This framing also deemphasises green content because it requires visitors to explore the webpages under this menu option before the content would be found, unless green content is also on the homepage.

The ability of main-menu titles to frame subset webpages was also evident in the case of the three websites which did not have green content on homepages (ePromo1, Teleco1, Teleco2) because it would potentially impact on whether visitors would find the content. For instance, if a visitor only wished to read about the firm's products-services then out of these websites only Teleco2's green content would have been accessed because its green content was located on its virtual servers (service) webpage. For the other websites the content would only have been accessed if the visitor explored other menu options.

\section{Environmental framing using navigation bars}

A fourth location theme related to whether and how SME websites incorporated green content into navigation bars. Du and Vieira (2012) implied that the menu titles listed were in the navigation bars of the large firms' websites but they did not identify this as a framing mechanism. Our findings suggest, at least in an SME context, that navigation bars should be considered a framing mechanism because those including green content in one of their navigation bars (all except eCRM, PrintMagazine, Teleco1, Teleco2, WebDev) framed the entire website in a green context. This is because the navigation bars, and thus the green content, were visible on all webpages with those bars. Websites which did not include green content in navigation bars, by contrast, de-emphasised the content because it was visible only by accessing specific webpages. However, the degree of emphasis for those including green content in their navigation bars depended on which bar(s). For example, ePromo1 was the only website with green content in the top bar while some websites de-emphasised the content by locating it in the bottom bar (ePromo2, ePromoPrint1, PrintProducts); often requiring scrolling down the webpage to be seen.

\section{Presentation of green content}

The second dimension grouped emergent themes relating to the presentation of green content. Our website analysis led to the categorisation of presentation approaches into three themes: textual forms (paragraphs and bullet points); emphasises in the textual forms such as section headings; and imagery such as photos. We examine each separately next.

\section{Textual forms: paragraphs and bullet points}

Table 2 summarises the first presentation theme which related to textual forms used to present green text: paragraphs entirely or partially including green content; and/or bullet lists entirely or partially including green actions, values/principles, commitments and/or product-service features. Du and Vieira 
(2012) did not identify entirely or partially green paragraphs and bullet point lists as framing mechanisms.

\begin{tabular}{|c|c|c|}
\hline Website & Paragraphs (all webpages) & Bullet point lists (all webpages) \\
\hline ePromoPrint2 & $\begin{array}{l}\text { Green text comprised } 7 \text { paragraphs of } 1-2 \\
\text { sentences each. }\end{array}$ & $\begin{array}{l}\text { Listed } 20 \text { green actions and named one green } \\
\text { award. }\end{array}$ \\
\hline ePromo2 & $\begin{array}{l}\text { Green text comprised } 7 \text { paragraphs of } 1-3 \\
\text { sentences each. }\end{array}$ & $\begin{array}{l}\text { Listed } 9 \text { green actions. } \\
\text { Listed } 7 \text { hyperlinks to information to help } \\
\text { visitors wanting to be green. }\end{array}$ \\
\hline WebHost & $\begin{array}{l}\text { Green text comprised } 18 \text { paragraphs of } 1-5 \\
\text { sentences each. }\end{array}$ & $\begin{array}{l}\text { Lists } 4 \text { green actions in addition to its carbon } \\
\text { neutral achievements. } \\
\text { Lists } 3 \text { features of its Web Hosting on the } \\
\text { homepage with one green feature. }\end{array}$ \\
\hline ePromoPrint 3 & $\begin{array}{l}\text { Green text comprised } 10 \text { paragraphs of 2-5 } \\
\text { sentences each. }\end{array}$ & $\begin{array}{l}\text { Lists } 7 \text { features of } 2 \text { types of business cards with } \\
2 \text { green features each. }\end{array}$ \\
\hline ePromoPrint 1 & $\begin{array}{l}\text { Green text comprised } 8 \text { paragraphs of } 1-4 \\
\text { sentences each. }\end{array}$ & $\begin{array}{l}\text { Listed } 3 \text { green features of its recycled paper } \\
\text { supplier or its products. }\end{array}$ \\
\hline WebDev & $\begin{array}{l}\text { Green text comprised } 10 \text { paragraphs of } 1-4 \\
\text { sentences each. }\end{array}$ & Not applicable. \\
\hline Teleco1 & $\begin{array}{l}\text { Green text comprised } 3 \text { paragraphs of } 1-2 \\
\text { sentences each. }\end{array}$ & Listed 4 green commitments of the firm. \\
\hline PrintMagazine & $\begin{array}{l}\text { Green text comprised } 1 \text { sentence of a 2-sentence } \\
\text { paragraph. }\end{array}$ & $\begin{array}{l}\text { Listed } 10 \text { ethical guidelines and } 4 \text { were green } \\
\text { practices. }\end{array}$ \\
\hline Teleco 2 & $\begin{array}{l}\text { Green text comprised less than half a } 2 \text {-sentence } \\
\text { paragraph. }\end{array}$ & $\begin{array}{l}\text { Listed } 7 \text { benefits of server consolidation and } 1 \\
\text { was green related. }\end{array}$ \\
\hline eCRM & $\begin{array}{l}\text { Green text comprised } 1 \text { paragraph of } 3 \text { short } \\
\text { sentences. }\end{array}$ & Not applicable. \\
\hline PrintProducts & $\begin{array}{l}\text { Green text comprised } 1 \text { sentence of } 2 \text {-sentence } \\
\text { product overviews. }\end{array}$ & Not applicable. \\
\hline ePromo1 & Not applicable. & $\begin{array}{l}\text { Listed } 14 \text { charities/not-for-profits supported and } \\
2 \text { were green initiatives. }\end{array}$ \\
\hline
\end{tabular}

Table 2: Textual forms of green content on the SME websites

The findings of this study (Table 2) suggests paragraphs and bullet lists are framing mechanisms in SME websites because some had paragraphs and lists which only partially embedded green content and therefore deemphasised the content by making it easier or harder for visitors to identify or find. This did not apply to websites with dedicated webpages (ePromoPrint2, ePromo2, ePromoPrint3, ePromoPrint1, WebHost and WebDev) because all the paragraphs or listed items were devoted to green content and was easier to find. This is apparent when considering websites (PrintMagazine, Teleco2, PrintProducts, ePromo1) which embedded the content within paragraphs and lists. The following example from Teleco 2 is typical and implies visitors would need to read the paragraph to find the content and that they may overlook the content due to the lack of emphasis:

"We consolidate your physical servers and support your business with less cost in addition to helping reduce your organisations environmental footprint. Your organisation can benefit from lower power, cooling and management costs."

The findings of this study also suggest that entirely green paragraphs on subset webpages could still be overlooked when they were embedded among many non-environmental paragraphs. For example, eCRM's paragraph devoted to green content on its "Ethical Policy" webpage was one of ten paragraphs as part of their ethical principles.

Overall, embedding green sentences, bullet list items or paragraphs amongst non-green content may result in visitors overlooking it unless other framing mechanisms are used to draw a visitor's attention to this content as explored next. 


\section{Section headings, coloured/bold text and hyperlinks}

The second presentation theme involved using one or more textual approaches to emphasise the green content: section headings, coloured and/or bold text, and hyperlinks. Du and Vieira (2012) did not identify these as framing mechanisms but our findings suggest that with the six websites (ePromoPrint3, ePromoPrint1, ePromoPrint2, WebHost, ePromo1, ePromo2) which used at least one of these approaches that these emphasised the green content. These can be contrasted with the remaining websites which only used paragraphs and lists (as reported in the previous section) without these framing mechanisms and which consequently deemphasised the green content.

The findings of this study suggest that section headings using environment-related words or phrases (e.g. "green", "recycled", "eco") can frame textual forms. Some subset webpages had headings which could draw attention to green content. For example, WebHost had an "Earth Hour" heading for one of its three news items on its "News and media centre" webpage. Interestingly, it was more common that subset webpages did not use green headings. For example, eCRM used a heading implying a broader societal context ("To our community") under which sat an entirely green paragraph, possibly assuming that visitors will logically connect it to environment issues, instead of a heading such as "To the environment". Other subset webpages did not use green headings at all. Green headings were more common on dedicated webpages with four websites (WebHost, ePromo2, ePromoPrint3, ePromoPrint1) which used environment-related green headings to break up the green content. For example, ePromoPrint3 had headings such as "More About Our Green Stock" and sub-headings such as "ECF (Elemental Chlorine Free) \& TCF (Totally Chlorine Free)" which helped to frame or contextualise the green paragraphs.

Additionally, the results of this study suggest that bold formatting and colours can emphasise or frame the green content on subset and dedicated webpages. Two websites (ePromoPrint1, ePromo2) used these approaches on their subset webpages, perhaps to draw visitors' attention to the entirely green paragraphs within the webpage. For example, ePromo2's subset webpage had two paragraphs whereby one was not green-related and the other was devoted to green activities. The following sentence within the latter paragraph had bolded, green coloured text "go green": "More recently we and our hosting division [Name] Hosting made a commitment to 'go green' and at no additional cost to our clients".

Four websites (ePromoPrint2, ePromoPrint3, ePromo1, ePromo2) had hyperlinks to internal webpages or external websites. Hyperlinks were often bolded and/or different colours compared to the surrounding text and were therefore more visible. This finding suggests that hyperlinks can also be used as a framing mechanism. This was most notable on ePromo1 which had a subset "Charity/Community Support" webpage listing various community organisations the firm supported. One list item included the bold and red hyperlink "No Carbon Here" which made this text more visible than other list items on the webpage.

\section{Imagery: logos, icons and photos}

The third presentation theme concerned the use of logos, icons and photos on nine of the 12 SME websites (see Table 3). In this paper we define icons as computer-drawn images (as opposed to photos) without text and logos as computer-drawn images with text. Du and Vieira (2012) identified multimedia as a framing mechanism because it is often more effective than text at conveying complex information and at attracting attention because they argue it is often seen before text. They focused on large firms' use of videos to convey green content which, at least in the SMEs we studied, did not apply. This raises the question of how other forms of imagery on SME websites can be used as framing mechanisms. 


\begin{tabular}{|c|c|c|}
\hline Website(s) & Image type & Logo/icon description \\
\hline $\begin{array}{l}\text { ePromo2, } \\
\text { WebDev } \\
\text { WebHost }\end{array}$ & $\begin{array}{l}\text { Third-party } \\
\text { logo }\end{array}$ & $\begin{array}{l}\text { A white rectangle with green text. Large "Green Power" and } \\
\text { smaller "Accredited Renewable Energy" beneath. Some } \\
\text { websites used a version with small green text "This business } \\
\text { powered by" above "Green Power". The logo was owned by } \\
\text { the Australian government and could be used when firms } \\
\text { purchased renewable energy plan from a provider accredited } \\
\text { by the government as renewable. }\end{array}$ \\
\hline $\begin{array}{l}\text { ePromoPrint2, } \\
\text { ePromo1, } \\
\text { WebDev, } \\
\text { WebHost }\end{array}$ & $\begin{array}{l}\text { Third-party } \\
\text { logo }\end{array}$ & $\begin{array}{l}\text { A black square with large, thick " } 60 " \text { text which shows an } \\
\text { image of the Earth with body of the text, and small white } \\
\text { "Earth Hour" text underneath. Firms could use this logo if } \\
\text { they participated in Earth Hour. }\end{array}$ \\
\hline ePromo1 & $\begin{array}{l}\text { Company } \\
\operatorname{logo}\end{array}$ & $\begin{array}{l}\text { A rectangle with dark green border and light green within, } \\
\text { dark green "no carbon here" with a leaf on the left, and a dark } \\
\text { green tick on right with "verified". This logo belonged to } \\
\text { another firm run by the owner-manager of ePromo1. }\end{array}$ \\
\hline & $\begin{array}{l}\text { Third-party } \\
\text { logo }\end{array}$ & $\begin{array}{l}\text { A white circle with image of the Earth (blue and green) with a } \\
\text { white tick through the middle and "Climate Positive" around } \\
\text { it in blue. This logo was owned by Climate Positive and could } \\
\text { be used by clients who purchased its carbon offsets. }\end{array}$ \\
\hline ePromo2 & Photo & $\begin{array}{l}\text { A black banner across the top of the webpage with an Earth } \\
\text { photo on the right and the Climate Positive logo in the lower } \\
\text { right hand corner. On the right was the name of the firm in } \\
\text { large white text, underneath "smarter greener [green text] } \\
\text { online solutions" and under in larger text "No extra cost to } \\
\text { you or the Earth..." }\end{array}$ \\
\hline \multirow{4}{*}{ ePromoPrint1 } & $\begin{array}{l}\text { Company } \\
\log 0\end{array}$ & $\begin{array}{l}\text { Four horizontal circles (blue, pink, yellow, black) with two } \\
\text { green leaves from the yellow circle and underneath green } \\
\text { larger text "printed with" and smaller text "vegetable based } \\
\text { inks" beneath this. }\end{array}$ \\
\hline & $\begin{array}{l}\text { Company } \\
\text { logo }\end{array}$ & $\begin{array}{l}\text { A green leaf-shaped image with "green news" in green } \\
\text { against a white background. }\end{array}$ \\
\hline & Icon & $\begin{array}{l}\text { A frog-shaped image with a green head and legs, orange feet } \\
\text { and eyes, a white stomach and tinges of blue. }\end{array}$ \\
\hline & Icon & $\begin{array}{l}\text { The recycling icon was similar to ePromoPrint2's except the } \\
\text { arrows were green against a white background. }\end{array}$ \\
\hline \multirow{3}{*}{ ePromoPrint 2} & Icon & $\begin{array}{l}\text { Three white, thick arrows in a triangular path in a clockwise } \\
\text { direction against a green background (that is, the universal } \\
\text { recycling symbol). }\end{array}$ \\
\hline & $\begin{array}{l}\text { Third-party } \\
\text { logo }\end{array}$ & $\begin{array}{l}\text { [Program] Partner: A rectangle with black/white text } \\
\text { "[Program] Partner" against a white/black background. Logo } \\
\text { was owned by a State government. Firms could use the logo } \\
\text { in promotions if they participated in the government program. }\end{array}$ \\
\hline & Photo & $\begin{array}{l}\text { Owner holding a certificate for completing the government } \\
\text { program. }\end{array}$ \\
\hline ePromoPrint 3 & $\begin{array}{l}\text { Third-party } \\
\text { logo }\end{array}$ & $\begin{array}{l}\text { Carbon Neutral: Five fanned leaf-shaped images of different } \\
\text { colours (green, black, yellow, magenta, blue) with Carbon }\end{array}$ \\
\hline
\end{tabular}




\begin{tabular}{|c|c|c|}
\hline & & $\begin{array}{l}\text { Neutral's trademark logo on the green leaf. Under this was } \\
\text { "we plant trees", then "carbon neutral GREEN member". }\end{array}$ \\
\hline & $\begin{array}{l}\text { Company } \\
\log 0\end{array}$ & $\begin{array}{l}\text { Shows on one side of a large "=" three fanned rectangles } \\
\text { (underneath "Print Business Cards" and on the other a green } \\
\text { tree image (underneath "Plant Trees"). }\end{array}$ \\
\hline & Icon & $\begin{array}{l}\text { Two green fanned rectangles (representing business cards) } \\
\text { and a green leaf-shaped image overlaying one of the } \\
\text { rectangles. }\end{array}$ \\
\hline & Icon & $\begin{array}{l}\text { The recycling icon was similar to ePromoPrint } 2 \text { except the } \\
\text { arrows were purple (on a white background) to match the } \\
\text { adjacent purple section heading. }\end{array}$ \\
\hline & Photo & $\begin{array}{l}\text { Webpage 1: photo of a forest with large text "Choose } \\
\text { Recycled" and above this in smaller text "Help save trees". } \\
\text { Webpage 2: photo of a hand holding a green plant and next to } \\
\text { this "we plant trees" and underneath "sustainable printing". }\end{array}$ \\
\hline Print-Magazine & Photo & $\begin{array}{l}\text { Homepage included an image of the magazine cover with the } \\
\text { firm's name with the by-line "Animal free food and living". }\end{array}$ \\
\hline PrintProducts & Photo & $\begin{array}{l}\text { A webpage for one diary had a photo of the cover showing a } \\
\text { lake, hills and a tree overlayed with a listing diary features } \\
\text { including "Enviro - contents printed on } 65 \% \text { PCW recycled } \\
\text { paper". }\end{array}$ \\
\hline WebDev & $\begin{array}{l}\text { Company } \\
\operatorname{logo}\end{array}$ & $\begin{array}{l}\text { White hollowed star with "Environmentally Friendly" in } \\
\text { white and located underneath. The image was enclosed in a } \\
\text { box with a background colour of green. }\end{array}$ \\
\hline WebHost & $\begin{array}{l}\text { Company } \\
\log 0\end{array}$ & $\begin{array}{l}\text { White text against a green circular background. The largest } \\
\text { text was the firm's initials "DP" in the centre (a small leaf at } \\
\text { the bottom of the "P") and, circling these initials, was "Eco } \\
\text { Host Powered by Green Hosting". The website states this } \\
\text { logo could be embedded on their clients' websites hosted by } \\
\text { WebHost. }\end{array}$ \\
\hline
\end{tabular}

Table 3: Summary of logos and icons used on SME websites

In the case of three websites with dedicated webpages (ePromoPrint1, ePromoPrint3, ePromo2) the images emphasised and complemented the text in a similar manner as for the subset webpages. However, some of the dedicated webpages differed because they also included third-party logos (ePromo2, ePromoPrint2, WebDev, WebHost) and, in one case, a photo of the owner-manager holding a certificate relating to the firm's green activities (ePromoPrint2). The next section on the specificity dimension considers the impact such images may have on the perception of credibility of the websites and their green claims.

\section{Specificity of green content}

The third dimension comprised of three emergent themes relating to website design approaches conveying or communicating varying degrees of legitimacy based on the extent of specificity of the green content. In line with legitimacy theory, the focus of these themes is on communication or legitimacy tactics firms can use on their websites to increase their credibility (Du \& Vieira, 2012). In other words, they concern how the websites describe the firm's green qualities of their processes, actions or products-services. 


\section{Statistics relating to the firm's green activities}

The first theme related to factual information in the form of statistics on the SME websites. This is consistent with the finding by Du and Vieira (2012) that legitimacy tactics on large firm websites were statements (especially statistics) on the amount of resources the firm devotes, or facts on the impact of their practices. Our findings suggest that on SME websites these statements of statistics can take various forms.

The first type of statistic related to the firm's environmental impact reduction as found by Du and Vieira (2012). These offer a greater sense of legitimacy compared to a statement that a firm has reduced its impact without statistics because it implicitly or explicitly states the firm is measuring their impact reductions. ePromo2 was the only website with such a statistic:

"We've implemented strategies to reduce our energy consumption in our offices that include turning off equipment and lighting not required and only leaving on critical equipment out of business hours. We are measuring the results of this and have seen more than a $25 \%$ reduction in our weekly electricity consumption."

This was an interesting finding because SME-specific research suggests they would have difficulty providing such statistics because SMEs often do not measure green outcomes (Clarke-Sather et al., 2011) or conduct audits (Brammer et al., 2012; Hofmann et al., 2012). Of even greater surprise was that with ePromoPrint 2 we discovered that the website of the government green program which the firm completed stated the percentage and quantity reductions made by ePromoPrint 2 in energy, greenhouse gases and waste. We were surprised the ePromoPrint 2 website itself did not include these statistics and this thus perhaps emphasises the notion that some SMEs may have, but choose not to communicate, these statistics. Alternatively, the website may not have been updated to include this information.

The second type of statistic which was more common on the SME websites was citing statistics about the third-party products they used from suppliers. For example, some cited statistics regarding the supplier's products such as stating they use " $100 \%$ recycled paper" (PrintMagazine, ePromoPrint1, ePromoPrint2, ePromoPrint3) or their recycled paper was made from " $100 \%$ post consumer waste" (ePromoPrint1). ePromoPrint3 included other statistics about its supplier's products: "During the process of making this recycled stock $92 \%$ of the energy used was renewable". Again, these statistics imply a greater level of legitimacy than similar statements without statistics because they imply measurement or specific details of "greenness" such as the proportion of recycled waste in recycled paper.

The final type of measurable numbers on two websites (ePromoPrint3, WebHost) was the inclusion of third-party statistics relating to the impact of their firm's industry on the environment or the benefits of national environmental initiatives. For example, WebHost cited supporting quantifiable evidence from third party sources to substantiate the impact of their industry on the environment and the total carbon emissions businesses in their industry generate. ePromoPrint3 cited statistics about the emission reductions which can be achieved from planting trees to justify why they planted a tree for every business card order.

These examples highlight that SMEs can provide a range of different types of statistics which may convey legitimacy in addition to the more difficult task of measuring their reduced environmental impact. The next section outlines another form of factual information.

\section{Specifics of green qualities of the firm's processes, actions and/or products-services}

The second theme concerned varying degrees of detail provided on the SME websites about the green qualities of the firm's products-services, processes and/or actions. Du and Vieira (2012) did not identify 
this theme as a legitimacy tactic but our findings, especially when comparing the different levels of detail provided via SME websites, suggests this is a relevant legitimacy theme.

The first example of this specificity theme related to the amount of detail provided by nine websites which mentioned green credentials of the firm's products-services. Of the nine websites, three (ePromo1, PrintMagazine, Teleco2) provided no/little detail on how or why the products-services reduced environmental impact. Two websites provided some detail such as general statements of policies/practices which ensure their services reduce impact (Teleco1) or the percentage of postconsumer waste comprising the paper in one of its diaries (PrintProducts). Four websites provided more comprehensive details of how they achieved carbon neutrality for their web hosting services (ePromo2, WebHost) or the credentials of the recycled paper used in their print products (ePromoPrint 3 and ePromoPrint1). The latter examples are likely to be seen as more credible because the detail provides specifics on why and how the products-services reduce environmental impact, although it is still up to visitors to decide if they believe this detail.

A second example related to variations in how the websites described the firm's green processes. For example, ePromo1 had a logo stating "No Carbon Here - Verified" but did not provide any information about how this was achieved. This can be contrasted with WebHost which provided specific detail about the process by which it made its website hosting service carbon neutral, adding a sense of legitimacy to the firm's claims:

"[WebHost] has committed to conducting Quarterly reviews of its carbon footprint, estimating the emissions generated for every aspect of its business including the daily operation and maintenance of hosting servers, routers and air conditioners. Following each review the company will purchase carbon credits to cover one hundred per cent of its estimated emissions. This ensures that whatever power [WebHost] uses, an equivalent amount is fed back into the electricity grid from wind or solar power, rather than non-sustainable means."

A third example related to the detail provided about the firm's green actions. For instance, eCRM merely stated it reduces paper. Some websites by contrast, as exemplified by ePromoPrint2, provided details of how they reduced paper such as: "Utilizing old sheets of paper for writing notes instead of purchasing writing pads; Reduction in printing of emails, by saving straight to the clients file; Proofs, proposals and invoices are delivered electronically saving on paper, ink cartridges, postage and envelopes; ...". This extra detail adds a greater sense of legitimacy because the basis of the firm's claim that it reduces paper is made clearer with the specific examples provided.

Overall, these findings suggest that a communication tactic which SMEs can use to increase the legitimacy or credibility of their green claims, in the absence of statistics, is to provide more detail about what they do, how they to it and why this means they are reducing their environmental impact. This detail does not necessarily prove, however, the firm employed these initiatives. This is where thirdparty substantiation might help, as explored next.

\section{Third-party evidence substantiating the firm's green claims}

The third theme related to the inclusion of details about third-parties on SME websites which can substantiate the green claims made by the firm. This theme is consistent with Du and Vieira (2012) who found in their study of large firm websites that a legitimacy tactic used by some firms was to provide details about third-party awards and certifications. Our findings suggest that SME websites can use various types of third-party substantiation.

One example noted earlier was using third-party logos (ePromo2, ePromoPrint2, WebDev, WebHost) to substantiate, for instance, that firms' use of renewable energy or participation in a program was legitimate. The perception of credibility depends, however, on whether visitors recognise and trust the logos (see Echegaray, 2014) and/or are prepared to click the logos to hyperlink to an external website 
to learn more. It also depends on whether the third-parties police the logos and/or list firms on their own website which use the products-services or have participated so that visitors have information to verify the firm's claims. For example, the website of the government green program in which ePromoPrint2 participated included this SME in the list of participants and verified it was a certified "Partner". Other third-parties such as Earth Hour did not provide a list of all firms which registered as participants, perhaps because participation cannot be verified and due to the numbers of firms taking part globally.

Some websites supplemented third-party logos by providing additional specificity about the third-party so that visitors could verify the firm's green claims. For example, ePromoPrint 2 provided a long description of the government program they participated in including: "[The program] assists businesses to identify efficiencies in waste, water and energy for financial and environmental benefits. [The program] has allowed us to record and register our improved environmental practise in the office...". As noted earlier, the owner also had a photo of herself holding her certificate from the program. A second example was ePromo2 which stated the name of the renewable energy plan they use: "Our offices and [Name] Data centre are now using [Plan Name], a GreenPower accredited option provided by [Supplier Name]". The latter example is worth noting because, while a visitor cannot verify if the SME is actually using the plan, it does show that a few specific words can be sufficient for a visitor to verify on the provider's website, if they wish, that the plan uses renewable energy.

A third, somewhat interesting finding, was from ePromoPrint1 because it provided details about thirdparty verification of the green credentials of their supplier's recycled paper:

"[Supplier] operate a closed loop energy system, meaning all by-products and wastes are reused as fuel for the paper mill. [Supplier] take pride in the fact that no waste leaves their premises. Remaining low levels of CO2 emissions, caused during manufacture, have been offset through the independently audited and government certified organisation [Climate Company]."

This finding is interesting because it suggests that a legitimacy tactic SMEs can use is to include information from its supplier on their own website. As with the previous example from ePromo2, if supplier names are provided visitors can verify the accuracy of the details.

A final example was an award for green activities which was listed among various other awards displayed on ePromoPrint 2 website. These awards give a greater sense of legitimacy because they imply that the firm's claims have been verified by third-party judges. Visitors could, if they wish, check the website of the third-party which makes the award to verify that the SME is a recipient and to determine how the award is judged, for example whether the award was made on the basis of SME self-reporting or verifications.

\section{CONCLUSION}

\section{Contribution to knowledge}

Table 4 summarises the paper and its contribution to knowledge. The first two columns present the framework (comprising three dimensions-location, presentation and specificity-and their components). They also answer the research question "What theory helps conceptualise how SMEs embed green content in their websites?" by summarising the framework components based on framing and legitimacy theories. Framing theory suggests the location and presentation components can be used to emphasise green content or frame the website as green. Legitimacy theory implies the components of the specificity dimension can be used as tactics to increase the credibility of green content by including, for instance, statistics and third-party substantiation relating to the firm's green activities. The third column highlights the main contribution to knowledge by showing the paper confirms 
(indicated by " $\checkmark$ ") or extends (indicated by "+") the use of framing and legitimacy theories by Du and Vieira (2012) to conceptualise new themes relating to how SME websites can embed green content. We noted earlier that few studies have investigated how specific content types are incorporated into SME websites in general, and this paper has addressed this gap in knowledge in the context of green content. The fourth column summarises the findings of this study using the framework.

\begin{tabular}{|c|c|c|c|}
\hline Location & Framing theory & & Findings summary using the framework \\
\hline $\begin{array}{l}\text { Clicks from the } \\
\text { homepage }\end{array}$ & $\begin{array}{l}\text { The more clicks needed } \\
\text { from homepages to reach } \\
\text { the content, the less a } \\
\text { website will be framed by } \\
\text { the content (Du \& Vieira, } \\
\text { 2012) }\end{array}$ & $\sqrt{ }$ & $\begin{array}{l}\text { Some SME websites were framed green by } \\
\text { locating green content on the homepage } \\
\text { (zero clicks). Others deemphasised it by } \\
\text { locating it one or two clicks from the } \\
\text { homepage. }\end{array}$ \\
\hline $\begin{array}{l}\text { Dedicated } \\
\text { versus subset } \\
\text { webpages }\end{array}$ & $\begin{array}{l}\text { The more webpages are } \\
\text { dedicated to the content, the } \\
\text { more a website will be } \\
\text { framed by the content }\end{array}$ & + & $\begin{array}{l}\text { Some SME websites were framed green by } \\
\text { dedicating 1+ webpages to green content. } \\
\text { Others located green content on webpages } \\
\text { with other content and thus deemphasised } \\
\text { it. }\end{array}$ \\
\hline $\begin{array}{l}\text { Titles of subset } \\
\text { or dedicated } \\
\text { webpages }\end{array}$ & $\begin{array}{l}\text { The more dedicated and } \\
\text { subset webpages which } \\
\text { have titles relating to the } \\
\text { content, the more a website } \\
\text { will be framed by the } \\
\text { content }\end{array}$ & + & $\begin{array}{l}\text { Green titles framed all dedicated and some } \\
\text { subset webpages as green content. Most } \\
\text { subset webpages had non-green titles which } \\
\text { deemphasised green content. Titles } \\
\text { contextualised or framed webpages (e.g. as } \\
\text { product-service, philosophy, etc). Many } \\
\text { SME dedicated and subset webpages which } \\
\text { were two clicks from the homepage were } \\
\text { deemphasised by being located or framed } \\
\text { under "About us" main-menus. }\end{array}$ \\
\hline Navigation bars & $\begin{array}{l}\text { The more (top) navigation } \\
\text { bars include links to the } \\
\text { content, the more a website } \\
\text { will be framed by the } \\
\text { content }\end{array}$ & + & $\begin{array}{l}\text { Some SME websites were framed green by } \\
\text { locating (links to) green content in } \\
\text { navigation bars so it was accessible from } \\
\text { webpages using these bars. The (links to) } \\
\text { green content were deemphasised on } \\
\text { bottom bars or emphasised on top bars. }\end{array}$ \\
\hline Presentation & Framing theory & & Findings summary using the framework \\
\hline $\begin{array}{l}\text { Lists/ } \\
\text { paragraphs } \\
\text { entirely or } \\
\text { partially devoted } \\
\text { to the content }\end{array}$ & $\begin{array}{l}\text { The more subset webpages } \\
\text { use lists/ paragraphs } \\
\text { devoted to the content, the } \\
\text { more a website will be } \\
\text { framed by the content }\end{array}$ & + & $\begin{array}{l}\text { Some SME subset webpages were framed } \\
\text { green to some extent with entirely green } \\
\text { paragraphs/bullet lists. Others } \\
\text { deemphasised green content by embedding } \\
\text { it in paragraphs/bullet lists on other topics. }\end{array}$ \\
\hline Section headings & $\begin{array}{l}\text { The more subset webpages } \\
\text { use headings devoted to the } \\
\text { content, the more a website } \\
\text { will be framed by the } \\
\text { content }\end{array}$ & + & $\begin{array}{l}\text { Some SME subset webpages were framed } \\
\text { green to some extent with green headings. } \\
\text { Others deemphasised green content by not } \\
\text { using green headings. }\end{array}$ \\
\hline
\end{tabular}




\begin{tabular}{|c|c|c|c|}
\hline $\begin{array}{l}\text { Coloured/ bold } \\
\text { text }\end{array}$ & $\begin{array}{l}\text { The more subset webpages } \\
\text { bold/colour the content, the } \\
\text { more a website will be } \\
\text { framed by the content }\end{array}$ & + & $\begin{array}{l}\text { Some SME subset webpages were framed } \\
\text { green to some extent by bolding/colouring } \\
\text { green words/ phrases to stand out in } \\
\text { paragraphs. Others deemphasised green } \\
\text { content by not using these types of text } \\
\text { formatting. }\end{array}$ \\
\hline Hyperlinks & $\begin{array}{l}\text { The more subset webpages } \\
\text { have hyperlinks (with bold } \\
\text { and/or colour) relating to } \\
\text { the content, the more a } \\
\text { website will be framed by } \\
\text { the content }\end{array}$ & + & $\begin{array}{l}\text { Some SME subset webpages were framed } \\
\text { green to some extent by using hyperlinks } \\
\text { on green words/phrases which stood out by } \\
\text { being bold/ coloured. Others deemphasised } \\
\text { green content by not using hyperlinks to } \\
\text { green content. }\end{array}$ \\
\hline Multimedia & $\begin{array}{l}\text { The more subset webpages } \\
\text { use images/logos relating to } \\
\text { the content (Du \& Vieira, } \\
\text { 2012) which are large and } \\
\text { located toward the top of } \\
\text { the webpage, the more a } \\
\text { website will be framed by } \\
\text { the content }\end{array}$ & $\checkmark$ & $\begin{array}{l}\text { Some SME homepages were framed green } \\
\text { using images (logos) only and some } \\
\text { dedicated/subset webpages were framed } \\
\text { green using images (logos, icons, photos); } \\
\text { often complementing the text. Framing was } \\
\text { increased or decreased depending on image } \\
\text { size/location relative to non-green content } \\
\text { on subset webpages. Others deemphasised } \\
\text { green content by not using images at all. }\end{array}$ \\
\hline Specificity & Legitimacy theory & & Findings summary using the framework \\
\hline Statistics & $\begin{array}{l}\text { Statistics are legitimising } \\
\text { tactics suggesting } \\
\text { credibility by quantifying } \\
\text { claims relating to the } \\
\text { content (Du \& Vieira, 2012) }\end{array}$ & $\sqrt{ }$ & $\begin{array}{l}\text { Some SME websites used statistics on } \\
\text { reductions of their practices on the } \\
\text { environment, green third-party products or } \\
\text { their industry's green impact as legitimacy } \\
\text { tactics, giving a sense of credibility } \\
\text { compared to websites not using them. }\end{array}$ \\
\hline $\begin{array}{l}\text { Detail on firm's } \\
\text { products- } \\
\text { services, actions } \\
\text { or processes }\end{array}$ & $\begin{array}{l}\text { Details are legitimising } \\
\text { tactics suggesting } \\
\text { credibility by explaining or } \\
\text { qualifying how/why claims } \\
\text { relating to the content are } \\
\text { justifiable }\end{array}$ & + & $\begin{array}{l}\text { Some SME websites stated details of the } \\
\text { green qualities of their products-services, } \\
\text { processes and/or actions as legitimacy } \\
\text { tactics which gave a greater sense of } \\
\text { credibility compared to websites which } \\
\text { stated only brief/vague details. }\end{array}$ \\
\hline $\begin{array}{l}\text { Third-party } \\
\text { substantiation }\end{array}$ & $\begin{array}{l}\text { Third-party substantiations } \\
\text { are legitimising tactics } \\
\text { suggesting disinterested } \\
\text { parties have verified claims } \\
\text { relating to the content ( Du } \\
\text { \& Vieira, 2012) }\end{array}$ & $\sqrt{ }$ & $\begin{array}{l}\text { Some SME websites used third-party logos, } \\
\text { descriptions of third-party programs } \\
\text { verifying their green credentials, details of } \\
\text { third-party products-services used } \\
\text { (including third-party verification of these } \\
\text { supplier products-services) and/or awards } \\
\text { as legitimacy tactics. These gave a greater } \\
\text { sense of credibility compared to websites } \\
\text { not using these tactics. }\end{array}$ \\
\hline
\end{tabular}

Table 4: Framework: how SME websites embed green content $(\checkmark$ confirmed, + new theme $)$

While this paper focused on green content, we anticipate the framework could be used by researchers to examine how SME websites embed other optional content types such as: 1) social responsibility content (e.g. charity donations and/or free products-services to disadvantaged groups); and 2) content relating to the SME's identity (e.g. size, history, staff details, family/sole-proprietor ownership). This is why the third column of table 4 states "the content" generically rather than "green content". 
Scholars can use the location and presentation dimensions, informed by framing theory, to evaluate the degree to which SMEs frame their website using a selected content type and to develop a continuum model by which the content is embedded. Using the example of SME identity content, at one end of the continuum some owner-managers may see competitive advantage in promoting a small (family) business identity. Our framework could be used to define strong framing of this identity, such as displaying content relating to this identity prominently on the homepage, in navigation titles and in dedicated webpages. At the other extreme some may wish to hide their size. Our framework could be used to define subtle or limited framing of this identity, such as embedding such identity-related content in subset webpages, multiple clicks from the homepage, and/or using presentation techniques which de-emphasise it. Other SME websites will be between these extremes depending on which combinations of location and presentation components are used, and how they are used, to (de-)emphasise the small (family) business identity. Our framework could therefore be used to identify patterns of location/presentation dimension combinations for each "stage" in the continuum regarding how this content is embedded in SME websites.

Researchers can use the specificity dimension, informed by legitimacy theory, to evaluate the credibility of the selected content type based on how it is described in SME websites. This could include using this dimension's components to develop a continuum model of low through to highly credible forms of, for instance, social responsibility content.

The framework could be used by scholars for theoretically-informed evaluation of SME websites over time to see how embedding of specific content changes. For example, green IS researchers could determine whether a sample of SME websites: (de-)emphasise green content over time (based on the location and presentation dimensions) and in what ways; and increases/decreases the credibility of the green content (based on the specificity dimension). The framework could also be used to determine the basis on which SME websites in a particular industry sector evolve to become similar (or quite disparate) with regards to how they embed content on their green activities in their websites.

The framework can potentially be used by scholars to develop theoretically informed interview and survey instruments to compare what SME owner-managers are trying to achieve when embedding specific content in their websites, with what our framework suggests is the case. Finally, researchers could use the framework to develop theoretically informed experiments with (SME) customers. For example, they could design different websites, based on combinations of the three dimensions, and survey consumers about the degree to which each design influenced their ability to find a specifically content type (e.g. social responsibility content) and/or their perception of the credibility of the content.

\section{Contribution to practice}

The presented framework suggests that proactive SMEs wishing to gain marketing advantage from their website should seriously consider framing and legitimacy design tactics. The concept of framing suggests these SME should identify the different types of content for the website and then, in order of importance, how prominent each type should be. The framing design tactics can then be used to prioritise the framing of each type of content appearing on the homepage, and then subsequently for what webpage titles should appear in the top navigation bar and so on. For example, if owner-managers believe all customers will like their green activities, social responsibility or small/family firm identity, the framing concept implies this content should not be delegated to the "About us" page but instead should be prominent on the homepage. The framing design tactics in the framework give ideas on how to achieve this. Importantly, the framework provides options for decreasing prominence of specific content, not just increasing it. For example, SMEs wishing to balance the needs of non-green and green customers could consider segregating green content from product-service webpages, and reducing the green framing (e.g. using partial green paragraph/bullet lists) to suit non-green customers. Finally, the 
legitimacy concept emphasises the need for specific details and preferably third-party substantiation of this content.

The framework also has potential policy implications. For example, we used the framework as a starting point for developing a new tool which governments, legal practitioners and industry associations can use to measure the quality of SME communication of their green activities online (see Parker et al. 2014). This includes governments using the tool to measure or evaluate the success of their interventions aimed at reducing the degree to which SMEs (due to their lack of marketing and legal skills) inadvertently mislead customers when promoting their green activities on their websites. Misleading promotions often result when firms, including SMEs, fail to provide evidence (e.g. statistics, third-party substantiation, detailed information about their green activities) of their marketing claims (ACCC, 2011).

\section{Limitations of the study and future research}

The study, leading to the framework in Table 4, has a number of limitations which can be addressed in future research. First, we concentrated on SME websites from the IMT sector, which were typically website developers, so the framework may be more indicative of IMT SMEs rather than SME with less website design experience. While the 12 websites identified through our research process were sufficient for the purposes of this study, future research might explore SME websites from other sectors to evaluate our framework. Second, the framework may reflect how green content is embedded in SME websites more so than other content types. Future research can explore how SMEs from other industry sectors and countries incorporate green, and other specific types of content, into their website designs. This work may identify further themes (or dimensions) which can be added to our framework and interpreted using framing and legitimacy theories.

\section{REFERENCES}

ACCC (2011) Green marketing and the Australian Consumer Law, Australian Competition and Consumer Commission, Canberra.

Alonso-Mendo, F., Fitzgerald, G. \& Frias-Martinez, E. (2009) "Understanding web site redesigns in small- and medium-sized enterprises (SMEs): a U.K.-based study on the applicability of ecommerce Stage Models", European Journal of Information Systems, Vol 18 No 3, pp 264-279.

Alonso Mendo, F. \& Fitzgerald, G. (2005) "A multidimensional framework for SME e-business progression", Journal of Enterprise Information Management, Vol 18 No 6, pp 678-696.

Andreopoulou, Z.S., Koutroumanidis, T. \& Manos, B. (2009) "The adoption of e-commerce for wood enterprises", International Journal of Business Information Systems, Vol 4 No 4, pp 440-459.

Aragon-Correa, J.A., Hurtado-Torres, N., Sharma, S. \& Garcia-Morales, V.J. (2008) "Environmental strategy and performance in small firms: a resource-based perspective", Journal of Environmental Management, Vol 86 No 1, pp 88-103.

Beck, A.C., Campbell, D. \& Shrives, P.J. (2010) "Content analysis in environmental reporting research: enrichment and rehearsal of the method in a British-German context", The British Accounting Review, Vol 42 No 3, pp 207-222.

Berente, N., Hansen, S., Pike, J.C. \& Bateman, P.J. (2011) "Arguing the value of virtual worlds: patterns of discursive sensemaking of an innovative technology", MIS Quarterly, Vol 35 No 3, pp 685709.

Bingley, S., Burgess, S., Sellitto, C., Cox, C. \& Buultjens, J. (2010) "A classification scheme for analysing Web 2.0 tourism websites", Journal of Electronic Commerce Research, Vol 11 No 4, pp 281-298. 
Brammer, S., Hoejmose, S. \& Marchant, K. (2012) "Environmental management in SMEs in the UK: practices, pressures and perceived benefits", Business Strategy and the Environment, Vol 21 No 7, pp 423-434.

Burgess, L., Parrish, B. \& Alcock, C. (2011) "To what extent are regional tourism organisations (RTOs) in Australia leveraging the benefits of web technology for destination marketing and eCommerce?", Electronic Commerce Research, Vol 11 No 3, pp 341-355.

Burgess, S. (2008) "Determining website content for small businesses: assisting the planning of owner/managers", International Journal of Knowledge Management Studies, Vol 2 No 1, pp 143-161.

Burgess, S. (2011) "The use of third party website providers by Australian small businesses", International Journal of Digital Society, Vol 2 No 1, pp 328-336.

Carey, J. (2008) "Role misconceptions and negotiations in small business owner/web developer relationships", Journal of Management and Organization, Vol 14 No 1, pp 85-99.

Cho, C.H. \& Roberts, R.W. (2010) "Environmental reporting on the internet by America's Toxic 100: legitimacy and self-presentation ", International Journal of Accounting Information Systems, Vol 11 No 1, pp 1-16.

Chong, D. \& Druckman, J.N. (2007) "Framing theory", Annual Review of Political Science, Vol 10, pp 103-126.

Clarke-Sather, A.R., Hutchins, M.J., Zhang, Q. \& Gershenson, J.K. (2011) "Development of social, environmental, and economic indicators for a small/medium enterprise", International Journal of Accounting and Information Management, Vol 19 No 3, pp 247-266.

Coffey, P., Tate, M. \& Toland, J. (2013) "Small business in a small country: attitudes to "Green" IT", Information Systems Frontiers, Vol 15 No 5, pp 761-778.

Cooper, J. \& Burgess, L. (2000) "A model of internet commerce adoption (MICA)", in: S.M. Rahman \& M.S. Raisinghani (eds) Electronic Commerce: Opportunity and Challenges, IGI Global, Hershey, Pennsylvania, pp 189-201.

de Vreese, C.H. (2005) "News framing: theory and typology", Information Design Journal + Document Design, Vol 13 No 1, pp 51-62.

Dick, G.N. \& Burns, M. (2011) "Green IT in small business: an exploratory study", 14th Southern Association for Information Systems Conference, 25-26 March, Atlanta, Georgia, USA.

Dincer, C. \& Dincer, B. (2010) "An investigation of Turkish small and medium-sized enterprises online CSR communication", Social Responsibility Journal, Vol 6 No 2, pp 197-207.

Du, S. \& Vieira, E.T., Jr. (2012) "Striving for legitimacy through corporate social responsibility: insights from oil companies", Journal of Business Ethics, Vol 110 No 4, pp 413-427.

Echegaray, F. (2014) "Understanding stakeholders' views and support for solar energy in Brazil", Journal of Cleaner Production, Vol 63, pp 125-133.

Elliot, S. (2009) "Developing organizational capabilities in SMEs: enabling environmentally sustainable ICT", 22nd Bled eConference, 14-17 June, Bled, Slovenia.

Fisher, J., Craig, A. \& Bentley, J. (2007) "Moving from a web presence to e-commerce: the importance of a business - web strategy for small-business owners", Electronic Markets, Vol 17 No 4, pp 253-262.

Goulding, C. (2005) Grounded Theory: A Practical Guide for Management, Business and Market Researchers, Sage, London, Thousand Oaks. 
Gueben, C. \& Skerratt, R.G. (2007) "SMEs and environmental communications: motivations and barriers to environmental reporting", International Journal of Environment and Sustainable Development, Vol 6 No 1, pp 1-16.

Herzig, C. \& Godemann, J. (2011) "Internet-supported sustainability reporting--expectations and reality: empirical findings from the German DAX30", in: M.A. Quaddus \& M.A.B. Siddique (eds) Handbook of Corporate Sustainability: Frameworks, Strategies and Tools, Edward Elgar, Cheltenham, UK, pp 249-281.

Hicks, K.E., Wogalter, M.S. \& Vigilante, W.J., Jr. (2005) "Placement of benefits and risks in prescription drug manufacturers' websites and information source expectations", Therapeutic Innovation \& Regulatory Science, Vol 39 No 3, pp 267-278.

Hofmann, K.H., Theyel, G. \& Wood, C.H. (2012) "Identifying firm capabilities as drivers of environmental management and sustainability practices - evidence from small and mediumsized manufacturers", Business Strategy and the Environment, Vol 21 No 8, pp 495-566.

Hsieh, Y.-C.J. (2012) "Hotel companies' environmental policies and practices: a content analysis of their web pages", International Journal of Contemporary Hospitality Management, Vol 24 No 1, pp 97-121.

Jiang, Y., Raghupathi, V. \& Raghupathi, W. (2009) "Content and design of corporate governance web sites", Information Systems Management, Vol 26 No 1, pp 13-27.

Jones, P., Simmons, G.J., Packham, G., Beynon-Davies, P. \& Pickernell, D. (2014) "An exploration of the attitudes and strategic responses of soleproprietor micro-enterprises in adopting information and communication technology", International Small Business Journal, Vol 32 No 3, pp 285306.

Keller, S. \& Coulthard, D. (2013) "Charting diversity and change in IS publications: a tri-continental journal analysis", Australasian Journal of Information Systems, Vol 18 No 1, pp 5-35.

LaRose, R. \& Rifon, N. (2006) "Your privacy is assured - of being disturbed: websites with and without privacy seals", New Media \& Society, Vol 8 No 6, pp 1009-1029.

Lei, C.F. \& Ngai, E.W.T. (2013) "Green IT adoption: an academic review of literature", 17th Pacific Asia Conference on Information Systems, 18-22 June, Jeju Island, Korea.

Lodhia, S. (2012) "Web based social and environmental communication in the Australian minerals industry: an application of media richness framework", Journal of Cleaner Production, Vol 25 No 1, pp 73-85.

MacGregor, R.C. \& Kartiwi, M. (2010) "Perception of barriers to e-commerce adoption in SMEs in a developed and developing country: a comparison between Australia and Indonesia", Journal of Electronic Commerce in Organizations, Vol 8 No 1, pp 61-82.

Matthes, J. \& Kohring, M. (2008) "The content analysis of media frames: toward improving reliability and validity", Journal of Communication, Vol 58 No 2, pp 258-279.

Melville, N.P. (2010) "Information systems innovation for environmental sustainability", MIS Quarterly, Vol 34 No 1, pp 1-21.

Mestre, L.S. (2011) "Visibility of diversity within Association of Research Libraries websites", The Journal of Academic Librarianship, Vol 37 No 2, pp 101-108.

Neilson, L.C., Madill, J. \& Haines, G.H., Jr. (2010) "The development of e-business in wine industry SMEs: an international perspective", International Journal of Electronic Business, Vol 8 No 2, pp 126-147.

Nielsen, A.E. \& Thomsen, C. (2009) "CSR communication in small and medium-sized enterprises: a study of the attitudes and beliefs of middle managers", Corporate Communications: An International Journal, Vol 14 No 2, pp 176-189. 
Nowduri, S. \& Al-Dossary, S. (2012) "Management information systems and its support to sustainable small and medium enterprises", International Journal of Business and Management, Vol 7 No 19, pp 125-131.

Park, Y.J. (2011) "Provision of Internet privacy and market conditions: an empirical analysis", Telecommunications Policy, Vol 35 No 7, pp 650-662.

Parker, C.M., Bellucci, E., Torlina, L., Fraunholz, B. \& Zutshi, A. (2014) "Towards a method for measuring the quality of environmental improvement communications on SME websites", Knowledge and Process Management, Vol 21 No 3, pp 187-197.

Parker, C.M. \& Castleman, T. (2007) "New directions for research on SME-eBusiness: insights from an analysis of journal articles from 2003 to 2006", Journal of Information Systems and Small Business, Vol 1 No 1-2, pp 21-40.

Parker, C.M., Fraunholz, B., Zutshi, A. \& Crofts, M. (2010) "How do Australian small and medium enterprises communicate their environmental improvement activities online?", Australasian Journal of Information Systems, Vol 17 No 1, pp 5-21.

Parker, C.M., Redmond, J. \& Simpson, M. (2009) "A review of interventions to encourage SMEs to make environmental improvements", Environment and Planning C: Government and Policy, Vol 27 No 2, pp 279-301.

Parker, C.M. \& Scheepers, R. (2012) "Applying King et al.'s taxonomy to frame the IS discipline's engagement in green IS discourse", 23rd Australasian Conference on Information Systems, 3-5 December, Geelong, Australia.

Parker, C.M., Zutshi, A., Fraunholz, B. \& Crofts, M.R. (2013) "A method for examining SME descriptions of environmental sustainability online", in: P. Ordonez de Pablos (ed.) Green Technologies and Business Practices: An IT Approach, IGI Global, Hershey, USA, pp 15-35.

Ramo, H. (2011) "Visualizing the phronetic organization: the case of photographs in CSR reports", Journal of Business Ethics, Vol 104 No 3, pp 371-387.

Resnick, M.L. \& Montania, R. (2003) "Perceptions of customer service, information privacy, and product quality from semiotic design features in an online web store", International Journal of Human-Computer Interaction, Vol 16 No 2, pp 211-234.

Revell, A., Stokes, D. \& Chen, H. (2010) "Small businesses and the environment: turning over a new leaf?", Business Strategy and the Environment, Vol 19 No 5, pp 273-288.

Saffu, K., Walker, J.H. \& Mazurek, M. (2012) "Perceived strategic value and e-commerce adoption among SMEs in Slovakia", Journal of Internet Commerce, Vol 11 No 1, pp 1-23.

Sanders, J. \& Galloway, L. (2013) "Rural small firms website quality in transition and market economies", Journal of Small Business and Enterprise Development, Vol 20 No 4, pp 788-806.

Sensis (2013) "Sensis e-Business Report: the online experience of small and medium enterprises", Sensis. http://about.sensis.com.au/DownloadDocument.ashx?DocumentID=484 (accessed 5 November 2013).

Spence, M., Boubaker Gherib, J.B. \& Biwole, V.O. (2011) "Sustainable entrepreneurship: is entrepreneurial will enough? A north-south comparison", Journal of Business Ethics, Vol 99 No 3, pp 335-367.

Strauss, A. \& Corbin, J.M. (1998) Basics of qualitative research: procedures and techniques for developing grounded theory, Sage, Thousands Oaks, California.

Tankard, J.W. (2001) "The empirical approach to the study of media framing", in: S.D. Reese, O.H. Gandy \& A.E. Grant (eds) Framing public life, Lawrence Erlbaum, Mahwah, New Jersey, pp 95-106. 
Tsai, J.Y., Egelman, S., Cranor, L. \& Acquisti, A. (2011) "The effect of online privacy information on purchasing behavior: an experimental study", Information Systems Research, Vol 22 No 2, pp 254-268.

Watson, R.T., Boudreau, M.-C. \& Chen, A.J. (2010) "Information systems and environmental sustainable development: energy informatics and new directions for the IS community", MIS Quarterly, Vol 34 No 1, pp 23-38.

Williams, S. \& Schaefer, A. (2013) "Small and medium-sized enterprises and sustainability: managers' values and engagement with environmental and climate change issues", Business Strategy and the Environment, Vol 22 No 3, pp 173-186.

Wymer, S. \& Regan, E. (2011) "Influential factors in the adoption and use of e-business and ecommerce information technology (EEIT) by small \& medium businesses", Journal of Electronic Commerce in Organizations, Vol 9 No 1, pp 56-82.

Yahoo Small Business Directory (2010) "Small business information from Kochie's business builders". http://smallbusiness.yahoo.com.au/SmallBusinessDirectory/SearchResults.aspx (accessed 31 December 2010).

Yu, J., Coulson, K.R., Zhou, J.X., Wen, H.J. \& Zhao, Q. (2011) "Communicating corporate environmental citizenship: an examination of Fortune 500 web sites", Journal of Internet Commerce, Vol 10 No 3, pp 193-207.

Zhu, Y., Basil, D.Z. \& Hunter, M.G. (2009) "The extended website stage model: a study of Canadian winery websites", Canadian Journal of Administrative Sciences, Vol 26 No 4, pp 286-300. 